\title{
Aesthetic Parameters and Patient-Perspective Assessment Tools for Maxillary Anterior Single Implants
}

\author{
Kelvin I. Afrashtehfar $\mathbb{D}^{\mathbb{D}},{ }^{1,2,3,4,5,6}$ Mansour K. A. Assery $\mathbb{D}^{7,7}$ and S. Ross Bryant $\mathbb{D}^{9,10}$ \\ ${ }^{1}$ Division of Restorative Dental Sciences, Department of Clinical Sciences, College of Dentistry, Ajman University, \\ 346 Ajman, UAE \\ ${ }^{2}$ Department of Reconstructive Dentistry and Gerodontology, School of Dental Medicine, Faculty of Medicine, University of Bern, \\ 3010 Berne CH, Switzerland \\ ${ }^{3}$ Vicerrectorado de Investigación-EIDUCAM, Universidad Católica San Antonio de Murcia (UCAM), 30107 Murcia, Spain \\ ${ }^{4}$ Department of Oral Surgery and Stomatology, School of Dental Medicine, Faculty of Medicine, University of Bern, \\ 3010 Berne CH, Switzerland \\ ${ }^{5}$ Department of Restorative Dentistry, Edinburgh Dental Institute, College of Medicine and Veterinary, University of Edinburgh, \\ Edinburgh EH3 9HA, UK \\ ${ }^{6}$ Centre of Medical and Bio-allied Health Sciences Research (CMBHSR), Ajman University, Dubai, UAE \\ ${ }^{7}$ Department of Prosthodontics, College of Dentistry, Riyadh Elm University, Riyadh 12611, Saudi Arabia \\ ${ }^{8}$ Postgraduate Studies and Scientific Research, Riyadh Elm University, Riyadh 12611, Saudi Arabia \\ ${ }^{9}$ Department of Oral Health Sciences, Faculty of Dentistry, University of British Columbia, Vancouver BC V6T 1Z3, Canada \\ ${ }^{10}$ Division of Prosthodontics and Dental Geriatrics, Faculty of Dentistry, University of British Columbia, \\ Vancouver BC V6T 1Z3, Canada
}

Correspondence should be addressed to Kelvin I. Afrashtehfar; kelvin.afrashtehfar@zmk.unibe.ch

Received 4 November 2020; Revised 4 December 2020; Accepted 17 December 2020; Published 17 February 2021

Academic Editor: Gaetano Isola

Copyright (C) 2021 Kelvin I. Afrashtehfar et al. This is an open access article distributed under the Creative Commons Attribution License, which permits unrestricted use, distribution, and reproduction in any medium, provided the original work is properly cited.

Background. This review aimed to concisely describe the current aesthetic objective indices for a single-implant maxillary anterior crown. The secondary aim was to propose introducing a unified, standardized questionnaire for adequately collecting patientreported outcome measures (PROMs) in implant dentistry. Materials and Methods. A literature review was conducted using both EMBASE/Ovid and MEDLINE/PubMed databases by combining keywords and Emtree/Mesh terms related to "Esthetics," "SelfAssessment or Surveys and Questionnaires," and "Single-Tooth Dental Implants." Results. The most meaningful aesthetic objective indices for single implants in the literature are the Pink Esthetic Score (PES), the Papilla Presence Index (PPI), Peri-Implant and Crown Index (PICI), PES/White Esthetic Score (PES/WES), the Implant Crown Aesthetic Index (ICAI), and a modified version of the ICAI (mod-ICAI) index. Clearly, PES/WES is still the most widely accepted tool. It is encouraging to observe that there is an increasing tendency in recent years to report PROMs more frequently in the implant dentistry literature. We proposed the implementation of a unified, standardized questionnaire using a self-administered visual analogue scale (VAS) scoring system, which evaluates overall satisfaction, comfort, tooth appearance, gingival appearance, function, and hygiene complexity. This tool should be validated in the oral implantology research context for its regular implementation or further development. Conclusions. Conducting qualitative studies among dental implant patients who received few implants or single-tooth implant reconstructions in the aesthetic zone may help dental researchers understand better how to efficiently develop and validate a quantitative instrument. This standard tool would reduce heterogeneity bias by providing comparable data between studies. 


\section{Introduction}

Single missing maxillary teeth in the aesthetic zone (i.e., tooth sites that are mostly visible in the smile) are increasingly managed with dental implants, especially in cases where the adjacent teeth are relatively free of disease or damage.

\subsection{Epidemiology of Missing Maxillary Anterior Teeth.} Although the prevalence of tooth loss has been decreasing in recent decades [1], up to one-quarter of adults in Western countries are missing at least one anterior tooth $[2,3]$. The aetiology of single missing permanent teeth in the aesthetic zone stems from either developmental hypodontia or acquired tooth loss. Hypodontia (i.e., tooth agenesis) is the most common developmental abnormality in humans [4], including those caused by both environmental and genetic factors [5-7]. Omitting third molars, the prevalence of hypodontia in the permanent dentition is reported to be up to 6.9\% [7]. Additionally, maxillary lateral incisors are some of the most prevalent congenitally missing permanent teeth $[8,9]$.

Acquired loss of anterior teeth at a young age is most frequently due to dental trauma, but over the adult lifespan, the aetiology will encompass broader, multifactorial origins, often including dental caries, as well as periodontal disease and less common causes [10-13], such as persisting oral habits and neoplasia [14]. The estimated prevalence of anterior dental trauma between the ages of 6 and 17 ranged widely across several studies from $6.4 \%$ to $37.9 \%$ [15].

1.2. Treatment for a Single-Tooth Edentulous Space in the Anterior Maxillary Zone. The traditional treatment for a single-tooth edentulous space in the anterior maxillary region has been a conventional three-unit or cantilever fixed dental prosthesis (FDP) [16, 17]. Two significant shortcomings of these alternatives are the need for significant tooth reduction of the abutments and an increased risk of dental caries, the most common cause of subsequent prosthesis failure [18]. Furthermore, subgingival FDP margins are often required in visible regions of the mouth, but these are associated with increased chronic gingival inflammation, leaving the patient at risk of more serious periodontal disease.

All these can be avoided if an implant is utilized to replace the missing tooth, especially when the teeth adjacent to the edentulous zone are sound [19]. It is well-established that single-tooth implants have favourable long-term survival rates [20]. Nevertheless, it is challenging to replace a single missing tooth in the aesthetic zone with an implant since hard and soft tissue resorption defects are often present [21-24]. In one study, out of a total of 2,381 dental implants placed at a university clinic, $492(20.8 \%)$ were placed in the anterior maxilla [25]. Frequent adjunct treatments to optimize the position and aesthetic results of such implants are bone grafting and soft tissue surgery. However, compromises to the final position and appearance often linger [21, 22, 26-33]. Patient-reported outcomes measures (PROMs) in dental medicine have been described as the fundamental "subjective" reports of patients' own perceptions of their oral health status and its impact on their daily life, including satisfaction with oral health status and other nonclinical assessments. However, PROMs have been underreported in almost all areas of dental medicine, and single-tooth implant treatment in the aesthetic zone is not the exception.

There is a need for reporting patient-reported outcome measures (PROMs) of single-tooth edentulous spaces in the anterior maxillary zone managed with a dental implant supporting a fixed reconstruction. Thus, this review aimed to concisely describe the current aesthetic objective indices for a single-implant maxillary anterior crown. The secondary aim was to propose introducing a unified, standardized questionnaire for adequately collecting PROMs in implant dentistry.

\section{Materials and Methods}

A narrative review approach was used for fulfilling the objectives of the present study. An electronic search was conducted aided by Embase/Ovid and MEDLINE/PubMed databases by combining keywords and Emtree/MeSH terms related to "Esthetics," "Self-Assessment or Surveys and Questionnaires," and "Single-Tooth Dental Implants." The search that supported the literature review was carried out up to July 12, 2020. This was complemented by manual searching the references of relevant studies. Forty-three studies met the selection criteria; however, not all studies were considered as there was duplication among some of the secondary sources. Mostly, review studies, clinical trials, and cases and controls were included. No meta-analyses were found.

\section{Results}

The present narrative review provides an insight into the most meaningful aesthetic objective indices for single implants in the dental literature.

3.1. Objective and Subjective Outcomes of Maxillary SingleImplant Anterior Teeth. Impaired appearance is the most apparent reason individuals seek to restore missing anterior teeth. Nonetheless, the primary focus of early literature on maxillary anterior implant outcomes was based on survival parameters, with a lack of information regarding aesthetically relevant parameters [34-36].

\subsection{There Is a Need for Reporting Patient-Reported Outcome} Measures (PROMs) in Dental Medicine. Aesthetic outcome parameters have evolved to include both subjective (patientmediated) and objective (dentist-mediated) quantitative outcomes [37-39]. In the process, researchers established that patient satisfaction was noticeably underreported in the early implant literature [36]. Subjective evaluation can be carried out using patient perceptions of the aesthetic outcome measured with specific questionnaires in which patients express their degree of satisfaction or dissatisfaction $[40,41]$. Such patient-reported outcome measures (PROMs) 
have the purpose of integrating patients' opinions, which offer valuable additional information beyond clinical outcome parameters $[42,43]$. The most popular formats for these PROMs are the Likert-type scale and the visual analogue scale (VAS) and, less commonly, a dichotomous coding system $[28,42]$.

Recent studies are now even more detailed on aesthetic outcomes than earlier reports of patient-based subjective satisfaction scores [37]. It has been pointed out that early reports on PROMs in implant dentistry focused on general patient satisfaction, which may not serve to adequately assess the range of impacts of implants on treatment outcomes as perceived by patients [44]. Thus, researchers have recommended adding more PROM-related detailed questions to give insight into a broader range of aspects that might affect patient satisfaction with implant prostheses [44].

\subsection{Current Aesthetic Objective Indices for a Single-Implant} Maxillary Anterior Crown. Several objective indices have been developed to assess clinician-mediated aesthetic outcomes for single-tooth implant restorations in the aesthetic zone [39, 45], including the Pink Esthetic Score (PES) [46], the Papilla Presence Index (PPI) [47], Peri-Implant and Crown Index (PICI) [45], PES/White Esthetic Score (PES/WES) [34], the Implant Crown Aesthetic Index (ICAI) [48], and a modified version of the ICAI (mod-ICAI) index [49] (Table 1).

While it is not in the scope of the present study to discuss in detail these aesthetic indices, a recent systematic review of studies using them identified unexplained variability across the studies in the correlations reported between subjective (i.e., patient-based) questionnaires and objective (i.e., clinician-mediated) assessments [37]. Among these studies, the subjective evaluation method was mostly conducted via VAS (eight out of eleven studies) and the remaining (three out of eleven studies) by a Likert-type scale (5- or 6-point rating). Overall, patients' subjective scores were either significantly higher when compared with clinicians' objective scores, or no significant correlation was found between these two groups of evaluators [37].

3.3.1. Example of a PES/WES Evaluation. This example displays a standardized intraoral front photograph with cheeks and lips retracted (Figure 1(a)) and a maxillary virtual cast model (i.e., Standard Tessellation Language (STL) file in Preview app version 7.0 (Apple Inc., Cupertino, CA, USA); Figure 1(b)) appraised by a validated objective aesthetic index such as the PES/WES $[34,50]$. Two experienced clinician researchers, calibrated for aesthetic analyses, independently evaluated these bidimensional and tridimensional objects with score sheets (Table 2). A score of $\geq 6$ (out of a maximum of 10) for either PES or WES and $\geq 12$ (out of a maximum of 20) for PES/WES combined were generally considered satisfactory. For example, the average score from both evaluators obtained from the single clinical scenario displayed in Figure 1 was 8/10, 8/10, and 16/20 for PES, WES, and PES/WES, respectively. Therefore, the three accumulated scores (i.e., PES, WES, and PES/WES) of the displayed clinical scenario were considered satisfactory.

\section{Discussion}

This review aimed to concisely acknowledge the current aesthetic objective indices for a single-implant maxillary anterior crown. A secondary aim was to propose introducing a unified, standardized questionnaire for adequately collecting PROMs in implant dentistry.

4.1. Potential Factors Influencing Patient Satisfaction with Maxillary Anterior Single-Tooth Implants. Naturally, patient satisfaction with maxillary anterior single-tooth implants is likely influenced by a range of additional outcomes, beyond aesthetics, broadly related to function, including maintenance and complications, as well as other personal and environmental influences such as body image, dentist-patient relationship, patients' expectations, and financial restrictions. Among these, personal influence is the importance that patients may place on dentists successfully re-establishing a comfortable oral function with stable dental occlusion [51-55].

Understanding patients' functional experiences, perhaps most notably involving chewing and speech, is useful for discussing realistic functional outcomes with patients relative to their expectations. For example, it is known that speech difficulties may be encountered, especially initially, with the installation of maxillary implant-supported fixed dental prostheses (ISFDPs) [56, 57].

Given the difficulty in parsing out the influence of aesthetics on patient satisfaction, having a more thorough explanation of these other potential factors from a patient perspective would likely be useful in further understanding patient satisfaction with maxillary anterior single-tooth implants. It would also be interesting to know about what would seem to likely be a substantial impact on the social life and self-perception of patients with a single implant in the aesthetic zone, although this has not been the focus of prior investigation.

4.1.1. Influence of Maintenance and Adverse Events. There is increasing information on the impact of maintenance care needed for dental implants, as well as the impact of potential technical complications over time [58-67]. For example, two qualitative studies have reported negative subjective experiences in some implant patients in terms of not being able to cleanse their ISFDPs properly $[56,57]$. Yet little is known regarding how satisfied patients are with the verbal or written instructions provided on maintaining single-tooth implants [68].

Gathering further information on patient experiences with maintenance may, therefore, help to develop strategies to improve both satisfaction and compliance with maintenance and preventive recommendations for maxillary anterior single-tooth implants. On the issue of the impact of complications, single-implant crowns are associated with an increased incidence of technical adverse events (i.e., ceramic fractures or chipping of the veneer material, abutment or screw loosening, and loss of retention) compared to traditional tooth-borne crowns and splinted-implant crowns 
TABLE 1: Criteria of the commonly used aesthetic indices and calculation of relative aesthetics.

\begin{tabular}{|c|c|c|c|c|}
\hline Items & PES & PES/WES & ICAI & PICI \\
\hline $\begin{array}{l}\text { Criteria of the peri-implant } \\
\text { mucosa }\end{array}$ & $\begin{array}{c}\text { Mesial papilla } \\
\text { Distal papilla } \\
\text { Level of soft-tissue } \\
\text { margin } \\
\text { Soft-tissue contour } \\
\text { Alveolar process } \\
\text { deficiency } \\
\text { Soft-tissue color } \\
\text { Soft-tissue texture }\end{array}$ & $\begin{array}{c}\text { Mesial papilla } \\
\text { Distal papilla } \\
\text { Facial curvature } \\
\text { Level of facial mucosa } \\
\text { Root convexity color }\end{array}$ & $\begin{array}{c}\text { Labial margin } \\
\text { Papillae } \\
\text { Contour of the labial } \\
\text { surface } \\
\text { Color and surface }\end{array}$ & $\begin{array}{c}\text { Papillae } \\
\text { Zenith } \\
\text { Root convexity }\end{array}$ \\
\hline Criteria of the implant crown & N/A & $\begin{array}{l}\text { Tooth form } \\
\text { Outline/volume } \\
\text { Color (hue/value) } \\
\text { Surface texture } \\
\text { Translucency and } \\
\text { characterization } \\
\end{array}$ & $\begin{array}{c}\text { Width } \\
\text { Length } \\
\text { Labial convexity } \\
\text { Color/translucency } \\
\text { Surface }\end{array}$ & $\begin{array}{c}\text { Shape } \\
\text { Color } \\
\text { Characterization }\end{array}$ \\
\hline Subjective overall criteria & None & None & None & $\begin{array}{c}\text { Crown } \\
\text { Mucosa } \\
\text { Overall (crown and } \\
\text { mucosa) }\end{array}$ \\
\hline Reference tooth & Contralateral tooth & Contralateral tooth & $\begin{array}{l}\text { Contralateral and } \\
\text { adjacent tooth }\end{array}$ & Contralateral tooth \\
\hline Scores per criteria & $\begin{array}{c}2 \text { (no deviation) } \\
1 \text { (small deviation) } \\
0 \text { (large deviation) }\end{array}$ & $\begin{array}{c}2 \text { (no deviation) } \\
1 \text { (small deviation) } \\
0 \text { (large deviation) }\end{array}$ & $\begin{array}{c}0 \text { (no deviation) } \\
1 \text { (small deviation) } \\
5 \text { (large deviation) }\end{array}$ & $\begin{array}{c}100 \mathrm{~mm} \text { visual analogue } \\
\text { scale }\end{array}$ \\
\hline Overall score (points) & $0-14$ & $0-20$ & $0-45$ & $0-600$ \\
\hline $\begin{array}{l}\text { Threshold of clinical } \\
\text { acceptability (points) }\end{array}$ & N/A & $\geq 12$ & $<5 \mathrm{P}$ & $\geq 360$ \\
\hline Calculation to percentage scale & N/A & $\begin{array}{c}0 \text { points }=0 \% \\
10 \text { points }=50 \% \\
20 \text { points }=100 \%\end{array}$ & $\begin{array}{c}0 \text { points }=100 \% \\
2.5 \text { points }=50 \% \\
5 \text { points }=0 \%\end{array}$ & $\begin{array}{c}0 \text { points }=0 \% \\
300 \text { points }=50 \% \\
600 \text { points }=100 \%\end{array}$ \\
\hline
\end{tabular}

PES, Pink Esthetic Score; PES/WES, PES/White Esthetic Score; ICAI, Implant Crown Aesthetic Index; PICI, Peri-Implant and Crown Index. The Papilla Index (PI) assesses the size of the interproximal gingival papilla height adjacent to implant-supported single-tooth restorations using a score from 0 to 4 : $0=$ no papilla present; $1=$ less than half of the papilla height is present, and a convex nature of the adjacent tissue is noted; $2=$ more than half of the papilla height is present but not to the full extent of the contact point (papilla is not in complete harmony); $3=$ the papilla fills the entire proximal space and is in good harmony; $4=$ the papilla is hyperplastic. Thus, a complete papilla formation will achieve 3 points.

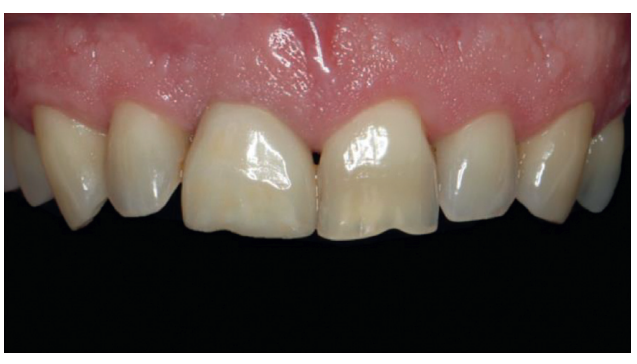

(a)

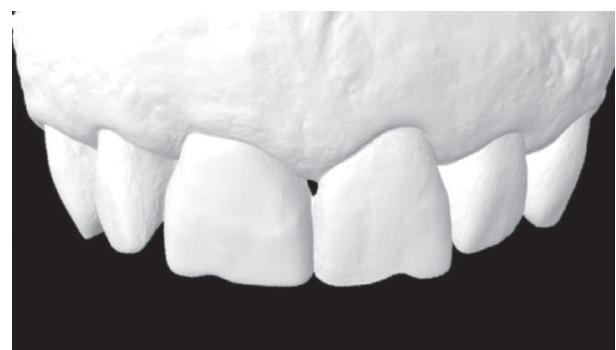

(b)

FIGURE 1: Dental records obtained from a male patient who had the right central incisor restored with a single implant-supported crown. (a) Maxillary anterior region with retracted cheeks and lips. (b) Digital image generated from the intraoral scanner.

[69-71]. However, the survival of single-implant crowns in the anterior region was higher than the three-unit FDP alternative in a 15-year follow-up study [72].

Although it is not a specific goal of the present review to include data on the prevalence and impact of complications, it is important to acknowledge their possibility since single-tooth implant patients' perspectives may be influenced by complications experienced after treatment delivery. Interestingly, one qualitative study has found that trust and confidence in their dentist may allow implant patients to be satisfied with treatment regardless of complications [56]. 
Table 2: Pink and White Esthetic Score sheets as interpreted by Belser et al. 2009.

Modified Pink Esthetic Score (PES)

Parameter

Major discrepancy Minor discrepancy No discrepancy

Parameter score

Mesial papilla

Distal papilla

Curvature of facial mucosa

Level of facial mucosa

Root convexity/soft tissue color and texture

0

Total PES score (maximum: 10)

Modified White Esthetic Score (WES)

Parameter

Major discrepancy Minor discrepancy No discrepancy

Parameter score

Tooth form

Tooth volume/outline

Color (hue/value)

Surface texture

Translucency

0

0

0

0

$\begin{array}{ll}1 & 2 \\ 1 & 2 \\ 1 & 2 \\ 1 & 2 \\ 1 & 2\end{array}$

(minimum: 0 maximum: 2)

Total PES score (maximum: 10)

4.2. The Proposed Standardized Questionnaire Used to Assess Patients' Self-Perceptions of Aesthetic Outcomes in Implant Dentistry. After identifying and appraising the available literature in implant dentistry used for patients assessing their own aesthetic outcomes, the authors (K. I. A., M. K. A., and S. R. B.) have proposed a standardized questionnaire that consists of a self-administered questionnaire that used a VAS, shown in (Table 3). The questionnaire included 6 items about the participants' perception of the single-tooth implant regarding overall satisfaction, comfort, tooth appearance, gum appearance, function, and cleaning complexity.

The proposed questionnaire may be used not only for single-tooth implant in the anterior zone but also for other fixed and removable prosthetic solutions assisted by dental implants. Nevertheless, the introduced questionnaire is expected to be validated for recommending it as the accepted tool to obtain PROMs from implant patients in future studies.

\subsection{Should We Opt for Qualitative Studies in Dental Medicine} to Obtain Rich "Subjective" Data? Qualitative studies in dentistry have the following objectives that could be relevant to further assessing patient perceptions relative to their treatment: to explore different aspects of patient experience, to identify areas for improvement in patient care, and to gather information on developing strategies to increase patient satisfaction and motivation towards their oral care services and health [73].

There have been a few qualitative studies published about tooth loss effects on patients' life experiences. Broadly speaking, these studies have shown that loss of teeth is related to low functional satisfaction and reduced social confidence, as well as self-image and self-esteem concerns [74].

4.3.1. Qualitative Studies in Implant Dentistry. There are only a few qualitative studies concerning patient accounts of their experiences with ISFDPs [75]. The few available studies
[56, 57, 76-78] reported that ISFDP-patients have acknowledged improvement on functionality [77, 78], confidence, social life, and self-image. However, sometimes there were concerns reported regarding initial speech difficulties $[56,57]$, excess salivation, tongue and cheek biting, altered food taste [57], and hygiene maintenance.

It has also been concluded that there is a need to further investigate dental implant patient expectations and future satisfaction, as well as experiences among patients with single-implant crowns, particularly among young patients [75].

4.3.2. Qualitative Studies Focusing on Single-Tooth Implants. The only qualitative study published on patients with singleimplant crowns was focused on understanding patient experiences with immediate implants in molar sites [79]. The study concluded that clinicians must more thoroughly explain the information related to implant longevity, prosthetic aspects, cost-effectiveness, and maintenance since participants had unrealistic expectations and inadequate information. Interestingly, the participants thought that their single molar implant did not influence their appearance and self-esteem. The study encouraged conducting additional qualitative research in implant dentistry [79].

There are no qualitative studies available related to patients with single-implant crowns in the anterior zone.

4.3.3. The Need for Qualitative Studies on Single-Tooth Implants in the Aesthetic Zone. A qualitative interview study is urgently required for patients with single implants in the anterior zone to explore satisfaction with their functional and aesthetic outcomes and to understand and improve the experiences of this sector of the dental population and improve communication with it. Therefore, we propose the future investigation of a range of qualitative issues related to the experiences and perceptions of the satisfaction of participants with their single-tooth implant in the maxillary anterior region. 
TABLE 3: The proposed standardized questionnaire used to subjectively assess patients' self-perceptions of aesthetic outcomes in implant dentistry.

(1) OVERALL SATISFACTION with your restored implant tooth

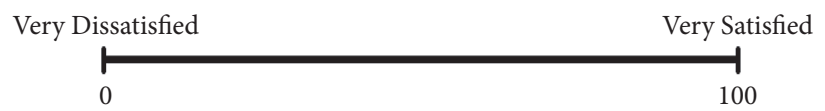

(2) OVERALL COMFORT with your implant tooth

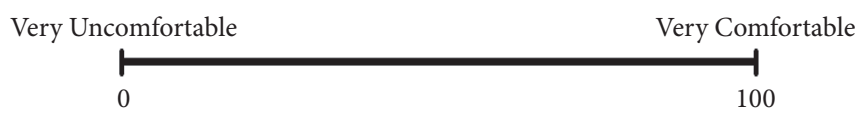

(3) Satisfaction with the APPEARANCE OF THE TOOTH (white portion) of your dental implant

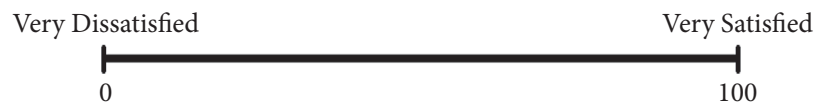

(4) Satisfaction with the APPEARANCE OF THE GUMS (pink portion) around your dental implant

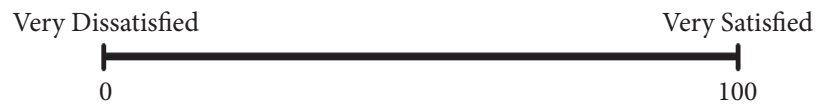

(5) OVERALL FUNCTIONING (for example, speech and chewing) with your implant tooth

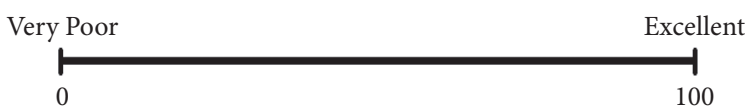

(6) CLEANING DIFFICULTY with your implant tooth

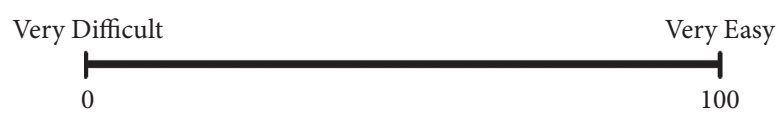

\section{Conclusions}

This literature review demonstrates that single-tooth anterior dental implants in the anterior are a viable treatment option, but that they can lead to some lingering challenges with the position of the implants and the soft tissue contours, in addition to some challenges with tooth color and contours, along with the potential for long-term complications and maintenance issues.

It is encouraging to observe that there is a tendency in recent years to report PROMs more frequently in the implant dentistry literature. Moreover, the forecast of this trend prepares the scientific consumers for an expected exponential growth in the dental literature reporting PROMs to the point that it may become a requirement for future studies to be considered for publication.

Objective and subjective indices have been developed to document and understand these issues' impact on patient satisfaction with the single-implant crown outcomes. The problem with these studies' findings is that they evidence an inconsistent and poorly explained relationship between patient satisfaction and objective indices of implant outcomes.

PES/WES is still the most widely accepted tool to assess the aesthetic outcomes of single implant-supported crowns in the maxillary anterior region from a clinician (objective) perspective despite introducing other indices aiming to improve the inter- and intraraterreliability of such a tool.

Several factors influence patient perspectives of implant treatment and add to the complexity of using the current nonvalidated and nonstandardized self-assessment questionnaires. Therefore, the present study introduces a unified, standardized questionnaire that consists of a self-administered questionnaire that used a VAS scoring system, which evaluates the overall satisfaction, comfort, tooth appearance, gum appearance, function, and cleaning complexity.

As an alternative to the introduced quantitative selfadministered questionnaire, conducting qualitative studies in dental implant patients who received few implants or single-tooth implant reconstructions in the aesthetic zone may help dental researchers understand better how to efficiently develop a new quantitative instrument that shall be further tested.

\section{Conflicts of Interest}

The authors declare that they have no conflicts of interest.

\section{Authors' Contributions}

KIA conceived the review idea; KIA and MKAA contributed to the literature review and article selection; KIA and SRB led 
the manuscript writing. All authors approved the final version of the submitted manuscript.

\section{Acknowledgments}

This work was generously supported by Ajman University, which had no role in the design, or interpretation of data, or any role in the decision to submit the results of the study for publication.

\section{References}

[1] G. D. Slade, A. A. Akinkugbe, and A. E. Sanders, "Projections of U. S. Edentulism prevalence following 5 decades of decline," Journal of Dental Research, vol. 93, no. 10, pp. 959-965, 2014.

[2] L. Meskin and L. Brown, "Prevalence and patterns of tooth loss in U. S. employed adult and senior populations, 1985-86," Journal of Dental Education, vol. 52, no. 12, pp. 686-691, 1988.

[3] S. E. Marcus, T. F. Drury, L. J. Brown, and G. R. Zion, "Tooth retention and tooth loss in the permanent dentition of adults: United States, 1988-1991," Journal of Dental Research, vol. 75, pp. 684-695, 1991.

[4] E. Matalova, J. Fleischmannova, P. T. Sharpe, and A. S. Tucker, "Tooth agenesis: from molecular genetics to molecular dentistry," Journal of Dental Research, vol. 87, no. 7, pp. 617-623, 2020.

[5] M. A. Williams and A. Letra, "The changing landscape in the genetic etiology of human tooth agenesis," Genes (Basel), vol. 95 pages, 2018.

[6] X. Ye and A. Attaie, "Genetic basis of nonsyndromic and syndromic tooth agenesis," Journal of Pediatric Genetics, vol. 05, no. 04, pp. 198-208, 2016.

[7] A. H. Al-Ani, J. S. Antoun, W. M. Thomson, T. R. Merriman, and M. Farella, "Hypodontia: an update on its etiology, classification, and clinical management," BioMed Research International, vol. 2017, Article ID 9378325, , 2017.

[8] T. Endo, R. Ozoe, M. Kubota, M. Akiyama, and S. Shimooka, "A survey of hypodontia in Japanese orthodontic patients," American Journal of Orthodontics and Dentofacial Orthopedics, vol. 129, no. 1, pp. 29-35, 2006.

[9] K. Khalaf, J. Miskelly, E. Voge, and T. V. Macfarlane, "Prevalence of hypodontia and associated factors: a systematic review and meta-analysis," Journal of Orthodontics, vol. 41, no. 4, pp. 299-316, 2020.

[10] G. Isola, A. Polizzi, A. Alibrandi, R. C. Williams, and R. Leonardi, "Independent impact of periodontitis and cardiovascular disease on elevated soluble urokinase-type plasminogen activator receptor (suPAR) levels," Journal of Periodontology, 2020.

[11] G. Isola, A. Polizzi, V. Iorio-Siciliano, A. Alibrandi, L. Ramaglia, and R. Leonardi, "Effectiveness of a nutraceutical agent in the non-surgical periodontal therapy: a randomized, controlled clinical trial," Clinical Oral Investigations, 2020.

[12] G. Isola, A. Polizzi, R. Patini, S. Ferlito, A. Alibrandi, and G. Palazzo, "Association among serum and salivary A. actinomycetemcomitans specific immunoglobulin antibodies and periodontitis," BMC Oral Health, vol. 20, no. 1, p. 283, 2020.

[13] G. Isola, A. L. Giudice, A. Polizzi, A. Alibrandi, R. Patini, and S. Ferlito, "Periodontitis and tooth loss have negative systemic impact on circulating progenitor cell levels: a clinical study," Genes (Basel), vol. 1012 pages, 2019.
[14] G. Krennmair, R. Seemann, M. Weinländer, W. Wegscheider, and E. Piehslinger, "Implant-prosthodontic rehabilitation of anterior partial edentulism: a clinical review," The International Journal of Oral \& Maxillofacial Implants, vol. 26, no. 5, pp. 1043-1050, 2011.

[15] D. Brullmann, R. K. Schulze, and B. D'Hoedt, “The treatment of anterior dental trauma," Dtsch Arztebl Int, vol. 108, no. 3435, pp. 565-570, 2011.

[16] M. Edelmayer, K. Woletz, C. Ulm, W. Zechner, and G. Tepper, "Patient information on treatment alternatives for missing single teeth-systematic review," European Journal of Oral Implantology, vol. 9, no. 1, pp. S45-S57, 2018.

[17] C. J. Goodacre and W. P. Naylor, "Single implant and crown versus fixed partial denture: a cost-benefit, patient-centred analysis," European Journal of Oral Implantology, vol. 9, no. 1, pp. S59-S68, 2020.

[18] J. N. Walton, F. M. Gardner, and J. R. Agar, "A survey of crown and fixed partial denture failures: length of service and reasons for replacement," The Journal of Prosthetic Dentistry, vol. 56, no. 4, pp. 416-421, 1986.

[19] R. Mericske-Stern, "Prosthetic considerations," Australian Dental Journal, vol. 53, no. 1, pp. S49-S59, 2008.

[20] D. Buser, V. Chappuis, U. C. Belser, and S. Chen, "Implant placement post extraction in esthetic single tooth sites: when immediate, when early, when late?" Periodontology, vol. 73, no. 1, pp. 84-102, 2000.

[21] V. Chappuis, M. G. Araujo, and D. Buser, "Clinical relevance of dimensional bone and soft tissue alterations post-extraction in esthetic sites," Periodontology, vol. 73, no. 1, pp. 73-83, 2000.

[22] T. Testori, T. Weinstein, F. Scutella, H. L. Wang, and G. Zucchelli, "Implant placement in the esthetic area: criteria for positioning single and multiple implants," Periodontology, vol. 77, no. 1, pp. 176-196, 2000.

[23] K. I. Afrashtehfar, "Why would someone refuse the best choice of treatment?" Journal of the New Jersey Dental Association, vol. 84, no. 3, pp. 11-12, 2013.

[24] K. I. Afrashtehfar and S. Esfandiari, "Five things to know about teeth in a day with dental implants," Journal of the New Jersey Dental Association, vol. 85, no. 1, pp. 24-25, 2016.

[25] A. A. Rasouli Ghahroudi, A. Homayouni, A. R. Rokn, F. Kia, M. J. Kharazifard, and A. Khorsand, "Frequency of dental implants placed in the esthetic zone in dental clinic of tehran university: a descriptive study," Journal of Dental (Tehran), vol. 12, no. 12, pp. 906-912, 2015.

[26] A. Barone, P. Toti, S. Marconcini, G. Derchi, M. Saverio, and U. Covani, "Esthetic outcome of implants placed in fresh extraction sockets by clinicians with or without experience: a medium-term retrospective evaluation," The International Journal of Oral \& Maxillofacial Implants, vol. 31, no. 6, pp. 1397-1406, 2016.

[27] V. Chappuis, L. Rahman, R. Buser, S. F. M. Janner, U. C. Belser, and D. Buser, "Effectiveness of contour augmentation with guided bone regeneration: 10-year results," Journal of Dental Research, vol. 97, no. 3, pp. 266-274, 2017.

[28] S. Del Monte, K. I. Afrashtehfar, E. Emami, S. Abi Nader, and F. Tamimi, "Lay preferences for dentogingival esthetic parameters: a systematic review," The Journal of Prosthetic Dentistry, vol. 118, no. 6, pp. 717-724, 2017.

[29] K. I. Afrashtehfar and M. K. Assery, "Five considerations in cosmetic and esthetic dentistry," Journal of the New Jersey Dental Association, vol. 85, no. 4, pp. 14-5, 2014.

[30] L. Z. G. Touyz and K. I. Afrashtehfar, "Cryogenically salvaged teeth as a potential source for grafting dentoalveolar, 
periodontal or maxillofacial defects," Medical Hypotheses, vol. 92, pp. 28-30, 2016.

[31] K. I. Afrashtehfar and A. Moshaverinia, "Five things to know about regenerative periodontal therapies in dental medicine," Journal of the New Jersey Dental Association, vol. 86, no. 2, pp. 12-13, 2015.

[32] K. I. Afrashtehfar and M. Del Fabbro, "Clinical performance of zirconia implants: a meta-review," The Journal of Prosthetic Dentistry, vol. 123, no. 3, pp. 419-426, 2020.

[33] K. Afrashtehfar, U. Brägger, and S. Hicklin, "Reliability of interproximal bone height measurements in bone-and tissuelevel implants: a methodological study for improved calibration purposes," The International Journal of Oral \& Maxillofacial Implants, vol. 35, no. 2, pp. 289-296, 2020.

[34] U. C. Belser, L. Grütter, F. Vailati, M. M. Bornstein, H.-P. Weber, and D. Buser, "Outcome evaluation of early placed maxillary anterior single-tooth implants using objective esthetic criteria: a cross-sectional, retrospective study in 45 patients with a 2 - to 4 -year follow-up using pink and white esthetic scores," Journal of Periodontology, vol. 80, no. 1, pp. 140-151, 2009.

[35] U. C. Belser, B. Schmid, F. Higginbottom, and D. Buser, "Outcome analysis of implant restorations located in the anterior maxilla: a review of the recent literature," The International Journal of Oral \& Maxillofacial Implants, vol. 19, pp. 30-42, 2004.

[36] L. Den Hartog, J. J. R. Huddleston Slater, A. Vissink, H. J. A. Meijer, and G. M. Raghoebar, "Treatment outcome of immediate, early and conventional single-tooth implants in the aesthetic zone: a systematic review to survival, bone level, soft-tissue, aesthetics and patient satisfaction," Journal of Clinical Periodontology, vol. 35, no. 12, pp. 1073-1086, 2008.

[37] S. P. Arunyanak, A. Pollini, A. Ntounis, and D. Morton, "Clinician assessments and patient perspectives of singletooth implant restorations in the esthetic zone of the maxilla: a systematic review," The Journal of Prosthetic Dentistry, vol. 118, no. 1, pp. 10-17, 2017.

[38] S. T. Chen and D. Buser, "Esthetic outcomes following immediate and early implant placement in the anterior maxilla-a systematic review," The International Journal of Oral \& Maxillofacial Implants, vol. 29, pp. 186-215, 2020.

[39] M. Hof, N. Umar, N. Budas, R. Seemann, B. Pommer, and W. Zechner, "Evaluation of implant esthetics using eight objective indices-Comparative analysis of reliability and validity," Clinical Oral Implants Research, vol. 29, no. 7, pp. 697-706, 2018.

[40] P. Gehrke, M. Lobert, and G. Dhom, "Reproducibility of the Pink Esthetic Score-Rating Soft Tissue Esthetics Around Single-Implant Restorations with Regard to Dental Observer Specialization," Journal of Esthetic and Restorative Dentistry, vol. 20, no. 6, pp. 375-384, 2008, discussion 385.

[41] M. Stefanini, P. Felice, C. Mazzotti, I. Mounssif, M. Marzadori, and G. Zucchelli, "Esthetic evaluation and patient-centered outcomes in single-tooth implant rehabilitation in the esthetic area," Periodontology, vol. 77, no. 1, pp. 150-164, 2000.

[42] C. J. Yao, C. Cao, M. M. Bornstein, and N. Mattheos, "Patientreported outcome measures of edentulous patients restored with implant-supported removable and fixed prostheses: a systematic review," Clinical Oral Implants Research, vol. 29, no. 16, pp. 241-254, 2018.

[43] K. I. Afrashtehfar and M. K. Assery, "From dental science to clinical practice: knowledge translation and evidence-based dentistry principles," The Saudi Dental Journal, vol. 29, no. 3, pp. 83-92, 2017.

[44] H. De Bruyn, S. Raes, C. Matthys, and J. Cosyn, "The current use of patient-centered/reported outcomes in implant dentistry: a systematic review," Clinical Oral Implants Research, vol. 26, no. 11, pp. 45-56, 2015.

[45] S. Tettamanti, C. Millen, J. Gavric et al., "Esthetic evaluation of implant crowns and peri-implant soft tissue in the anterior maxilla: comparison and reproducibility of three different indices," Clinical Implant Dentistry and Related Research, vol. 18, no. 3, pp. 517-526, 2016.

[46] R. Fürhauser, D. Florescu, T. Benesch, R. Haas, G. Mailath, and G. Watzek, "Evaluation of soft tissue around single-tooth implant crowns: the pink esthetic score," Clinical Oral Implants Research, vol. 16, no. 6, pp. 639-644, 2005.

[47] D. Cardaropoli, S. Re, and G. Corrente, "The Papilla Presence Index (PPI): a new system to assess interproximal papillary levels," International Journal of Periodontics and Restorative Dentistry, vol. 24, no. 5, pp. 488-492, 2020.

[48] H. J. A. Meijer, K. Stellingsma, L. Meijndert, and G. M. Raghoebar, "A new index for rating aesthetics of implant-supported single crowns and adjacent soft tissues - the Implant Crown Aesthetic Index," Clinical Oral Implants Research, vol. 16, no. 6, pp. 645-649, 2005.

[49] V. H. Vilhjalmsson, K. S. Klock, K. Storksen, and A. Bardsen, "Aesthetics of implant-supported single anterior maxillary crowns evaluated by objective indices and participants' perceptions," Clinical Oral Implants Research, vol. 22, no. 12, pp. 1399-1403, 2020.

[50] D. Buser, V. Chappuis, M. M. Bornstein, J. G. Wittneben, M. Frei, and U. C. Belser, "Long-term stability of contour augmentation with early implant placement following single tooth extraction in the esthetic zone: a prospective, crosssectional study in 41 patients with a 5-to 9-year follow-up," Journal of periodontology, vol. 84, no. 11, pp. 1517-27, 2013.

[51] U. C. Belser, R. Mericske-Stern, J.-P. Bernard, and T. D. Taylor, "Prosthetic management of the partially dentate patient with fixed implant restorations," Clinical Oral Implants Research, vol. 11, no. 1, pp. 126-145, 2000.

[52] U. C. Belser, J. P. Bernard, and D. Buser, "Implant-supported restorations in the anterior region: prosthetic considerations," Practical Periodontics and Aesthetic Dentistry: PPAD, vol. 8, no. 9, pp. 875-884, 1996, quiz 884.

[53] K. I. Afrashtehfar and U. C. Belser, "Prevention and Management of Cheek and/or Tongue Biting Related to Posterior Implant-Supported Fixed Dental Prostheses (ISFDPs)," Journal of Prosthodontics, vol. 28, no. 7, pp. 837-839, 2018.

[54] K. I. Afrashtehfar, U. Brägger, K. Igarashi, and U. C. Belser, "A modified technique for the intraoral assessment of static occlusal contacts," The Journal of Prosthetic Dentistry, vol. 119, no. 6, pp. 909-911, 2018.

[55] K. I. Afrashtehfar and S. Qadeer, "Computerized occlusal analysis as an alternative occlusal indicator," Cranio, vol. 34, no. 1, pp. 52-57, 2016.

[56] B. Narby, U. Hallberg, I. C. Bagewitz, and B. Soderfeldt, "Grounded theory on factors involved in the decision-making processes of patients treated with implant therapy," The International Journal of Prosthodontics, vol. 25, no. 3, pp. 270-278, 2012.

[57] A. Johannsen, A. Westergren, and G. Johannsen, "Dental implants from the patients perspective: transition from tooth loss, through amputation to implants - negative and positive trajectories," Journal of Clinical Periodontology, vol. 39, no. 7, pp. 681-687, 2012. 
[58] S. Todescan, S. Lavigne, and A. Kelekis-Cholakis, "Guidance for the maintenance care of dental implants: clinical review," Journal of the Canadian Dental Association, vol. 78, p. c107, 2020.

[59] A. S. Bidra, D. M. Daubert, L. T. Garcia et al., "A systematic review of recall regimen and maintenance regimen of patients with dental restorations. Part 2: implant-borne restorations," Journal of Prosthodontics, vol. 25, no. 1, pp. S16-S31, 2016.

[60] S. Humphrey, "Implant maintenance," Dental Clinics of North America, vol. 50, no. 3, pp. 463-478, 2014.

[61] A. Kelekis-Cholakis and J. Rothney, "Maintenance of implant patients: a narrative review," Implant Dent, vol. 28, no. 2, pp. 161-172, 2019.

[62] M.-S. Howe, "Implant maintenance treatment and peri-implant health," Evidence-Based Dentistry, vol. 18, no. 1, pp. 8-10, 2017.

[63] K. I. Afrashtehfar and S. Esfandiari, "Five things to know about peri-implant mucositis and peri-implantitis," Journal of the New Jersey Dental Association, vol. 88, no. 1, pp. 24-25, 2017.

[64] K. Igarashi, K. Afrashtehfar, M. Schimmel, A. Gazzaz, and U. Brägger, "Performance of a repair service set for the retrieval of fractured abutment screws: a pilot in vitro study," The International Journal of Oral \& Maxillofacial Implants, vol. 34, no. 3, pp. 567-573, 2019.

[65] K. Igarashi and K. I. Afrashtehfar, "Clinical assessment of fractured implant abutment screws: the Bernese silicone replica technique," Journal of Prosthetic Dentistry, vol. 119, no. 5, pp. 717-719, 2017.

[66] L. Z. G. Touyz and K. I. Afrashtehfar, "Implications of bisphosphonate calcium ion depletion interfering with desmosome epithelial seal in osseointegrated implants and pressure ulcers," Medical Hypotheses, vol. 107, pp. 22-25, 2017.

[67] A. Srivastava, K. I. Afrashtehfar, and S. Esfandiari, "How to manage a loosened dental implant associated with pain?" Journal of the Canadian Dental Association, vol. 80, p. e46, 2014.

[68] T. Walton and D. Layton, "Satisfaction and patient-related outcomes in 128 patients with single implant crowns in situ for up to 14 years," The International Journal of Oral \& Maxillofacial Implants, vol. 32, no. 3, pp. 667-674, 2017.

[69] M. Lewis and I. Klineberg, "Prosthodontic considerations designed to optimize outcomes for single-tooth implants. A review of the literature," Australian Dental Journal, vol. 56, no. 2, pp. 181-192, 2011.

[70] B. E. Pjetursson, U. Brägger, N. P. Lang, and M. Zwahlen, "Comparison of survival and complication rates of toothsupported fixed dental prostheses (FDPs) and implant-supported FDPs and single crowns (SCs)," Clinical Oral Implants Research, vol. 18, no. 3, pp. 97-113, 2007.

[71] A. Ravidà, M. H. A. Saleh, M. C. Muriel, B. Maska, and H.-L. Wang, "Biological and Technical Complications of Splinted or Nonsplinted Dental Implants," Implant Dentistry, vol. 27, no. 1, pp. 89-94, 2018.

[72] T. Walton, "An up-to-15-year comparison of the survival and complication burden of three-unit tooth-supported fixed dental prostheses and implant-supported single crowns," The International Journal of Oral \& Maxillofacial Implants, vol. 30, no. 4, pp. 851-861, 2015.

[73] W. C. John, Research Design. Qualitative, Quantitative, and Mixed Methods Approaches, Sage Publications, New York, CA, USA, 4th edition, 2013.
[74] G. Nordenram, T. Davidson, G. Gynther et al., "Qualitative studies of patients' perceptions of loss of teeth, the edentulous state and prosthetic rehabilitation: a systematic review with meta-synthesis," Acta Odontologica Scandinavica, vol. 71, no. 3-4, pp. 937-951, 2013.

[75] W. A. Kashbour, N. S. Rousseau, J. S. Ellis, and J. M. Thomason, "Patients' experiences of dental implant treatment: a literature review of key qualitative studies," Journal of Dentistry, vol. 43, no. 7, pp. 789-797, 2015.

[76] A. Lantto and I. Wårdh, "Dental implants in the functionally impaired: experience from the patients' perspective," Acta Odontologica Scandinavica, vol. 71, no. 3-4, pp. 525-533, 2013.

[77] U. Trulsson, P. Engstrand, U. Berggren, U. Nannmark, and P.-I. Brånemark, "Edentulousness and oral rehabilitation: experiences from the patients' perspective," European Journal of Oral Sciences, vol. 110, no. 6, pp. 417-424, 2002.

[78] E. B. Grey, D. Harcourt, D. O’Sullivan, H. Buchanan, and N. M. Kilpatrick, "A qualitative study of patients' motivations and expectations for dental implants," British Dental Journal, vol. 214, no. 1, p. E1, 2013.

[79] M. A. Atieh, K. C. Morgaine, and W. J. Duncan, "A qualitative analysis on participants' perspectives on oral implants," Clinical Oral Implants Research, vol. 27, no. 3, pp. 383-391, 2015. 